\title{
Satisfaction, Resilience and Achievement. Towards a Change in Priorities Within the Framework of New Sociocultural and Educational Paradigms
}

\author{
Miriam Aparicio \\ National Council of Scientific Research (CONICET). \\ National University of Cuyo ${ }^{1}$. \\ Mendoza, Argentina.
}

\begin{abstract}
The importance of Satisfaction and Resilience is shown (linked to numerous "social competencies") in processes of Academic and Professional Achievement in various contexts (scientific, academic, professional). The results support empirical research linked to academic-professional pathways. Our objective was to explain the factors associated with achievement (included as conditions or effects within the models, as independent or dependent variables) and to understand the "reasons" and "processes" that underlie the numerical results (statistics, rankings). These included base, psychosocial, pedagogical-institutional, organizational and structural factors. In particular, we sought to observe the weight of psychosocial variables, which the author named "social competencies" 20 years ago and which today are prioritized ("soft skills") by countries that lead the rankings in educational quality. Among these, Resilience and Satisfaction have recently been incorporated by PISA (2014) for their importance for achievement within the learning paradigm. A synthesis of studies is presented in which these variables' weight is shown. The strategy for analysis was micro-meso-macro-micro in light of the author's theory of three interacting levels or The Three-Dimensional Spiral of Sense. The results show that -as the basis for achievement or as an associated effect- social competencies play a key role in facilitating learning. Without listening, communication, implication, engagement, satisfaction, solid relationships and strategies for overcoming adversity, both learning as well as integral changes in education systems that respond to new demands will be difficult to produce, as will changes at the individual and institutional levels.
\end{abstract}

Keywords: Satisfaction - Resilience - Achievement - Social Competencies - New Paradigm

\section{Introduction}

In this era of knowledge, and from a paradigm of learning where what is most important is learning how to learn, educational priorities in developed countries have changed to incorporate skills and competencies, whereas before education was restricted to disciplinary knowledge and excluded knowing how to do, how to be, how to live and how to be happy. These all become necessary in the context of dramatic changes that place value not only on the knowledge one has but also on "what one is able to do with that knowledge." This involves the development of creativity, flexibility, a critical eye, openmindedness, recognition, decision-making and negotiation abilities and related competencies.

Globally, this change in priorities can be observed at two levels:

a) At the level of education, said skills/competencies have evolved looking towards the demands of the future, towards the "future of the workplace" or "workplace of the future", each with its own connotations. Competencies that were developed 10 years ago and those that are currently prioritized are located at different ends of the spectrum in countries that lead the rankings of institutional quality and learning (OECD. World Economic Forum "Future of jobs report"). These competencies, more developed in some countries than in others, -within a model that links determining factors with effects- generally enter as factors determining individual/professional achievement. From the author's perspective, and through added effects, these factors influence the respective institutional quality and lead to improvements at the national level (macro level,

${ }^{1}$ With financing from PICTO 20016-0008. PRESTAMO BID. MIRIAM APARICIO. 
reflected in country rankings) (Aparicio, $2015 \mathrm{a}, \mathrm{b}$ ).

b) In terms of the expected or most valued effects, both in academic and workplace systems (more precisely in the educational systems that lead the rankings), there are two factors to recover and attempt to measure. On the one hand, the factor/dimension of Satisfaction and achievement of better conditions, both academic (a climate of collaboration, founded on motivation and individual interest) and professional (healthy relationships with colleagues and bosses, greater transversality without limiting authority and opportunities for continuing education) (Mostafa \& Pál, 2018). On the other hand, the factor of Resilience or ability to cope with adversity in a complex world where one must learn strategies to deal with unexpected situations in the academic institution and in life (problem-solving, coping) (Agacisti et al, 2018).,PISA (Programme for International Student Assessment), which measures Language, Mathematics and Reading performance of teenage students in 72 countries, began to compare these two factors in 2014.

Previously, countries were concerned with being highly ranked and being aware of professional mobility, with overcoming social inequalities in broad terms and with reaching greater equity; now, in a global and competitive world which is ever more demanding, it is also important to study aspects such as satisfaction (an effect reached within a system) and resilience (a condition for achievement in difficult contexts or the result of the co-construction of bonds between individuals and institutions/communities).

Interest is centered on individuals, conditioned by their contexts which are limiting but not determining (in this line, some countries show high results for all levels of society, a fact which represents advances in terms of equity).

What's more, revaluing said "soft" skills and competencies which are more related to the subjective level (Chernyshenko, Kankaraš \& Drasgow, 2018), indicates that there is a certain return to the individual in the epistemic and sociologicalcultural paradigms at the base of the current educational paradigm shift: the learning paradigm. The interactionist paradigm (Boudon, 1973) and the "grammaires de l'individu" (Martucelli, 2002) would oppose hyperfunctionalism and the "grammaire genétique- structurelle" of Bourdieu and Passeron (1979). An individual's achievement is not determined only by his origin, mediated by the school (reproducer of bourgeois cultural codes and social classes), but is conditioned by the development of multiple abilities/competencies (among them psychosocial competencies) as part of the educational system, a system that is now demanding rapid, equal and integrative changes in many countries, including Argentina, and that involves both politicians and educators as well as students, the system's main actors. Thus, three systems in interaction.

\section{Brief Theoretical Framework: Research focus}

Here we take up certain approaches that guided our research and which we will detail as follows.

As opposed to PISA: a) our research deals with quantitative-qualitative investigations in the "field", carried out from a systemic perspective sui generis using interactive models that shed light on the "goings" and "comings" (feedback) within the individual and educational micro-systems as related to the workplace and of all systems in sustained interaction (recursive spiral movements with advances and relapses, with positive and negative effects, not linear but rather dynamic) (Aparicio, 2007; 2009 a, b; d, 2016). In fact, learning and results are also observed in organizational contexts (Shön, 1992; Argyris, 1982). b) We work with university students rather than with adolescents, which highlights the fact that resilience and satisfaction continue to be relevant factors over time. c) Our strategy of analysis was micro-meso-macro-micro, which has not been well developed in our field. d) Using this strategy, we attempt to capture, from a comprehensive perspective (Dubar, 1995; Boudon, 1973), the "reasons" that underlie an individual's achievement or failure and the "meaning" that they find in their behavior, using a personalized investigation that helps to listen to the actors, their problems and from their experience. e) Our models include not only numerical inputs and outputs but also psychosocial/relational, cultural and cognitive processes, processes that mediate results. f) Opting for a systemic paradigm sui generis (far from its biological or administrative origins) emerges from the absence of quantitative-qualitative integrative studies that cover long periods of time (not only synchronic but also diachronic and even longitudinal). During these periods, important macro-structural changes are produced in policy, in education systems, in evaluation and in employment (new systems of recruiting, prioritization of certain competencies in contexts of growing competition, different models of human resources and management). All of this results in greater or lesser opportunities for academic achievement (entrance, permanence, graduation); for workplace achievement (insertion according to education, promotion, dignified working conditions) and for individual achievement (according to aspirations, goals, perspectives for the future and life projects). Only studies over broad ranges of time and space allow for an observation of processes of inter-systemic feedback and of the inside of each 
micro-system, pillars of the author's theory.

Finally, we must remember that this research had as its focus an improvement in the quality both of the education system and of employment. This is an issue that began to appear at the center of the political agenda in the 1990s and that is still difficult to give shape to, particularly when taking into account the criteria of relevance or the response that the education system provides when faced with new problems and social crises in contexts of growing competition, looking to the requirements of the future and to long-term country projects.

\section{Empirical Research: Focus and Results}

The following are studies that include Satisfaction and Resilience, both in the academic system and the workplace, and that reveal the quantitative weight (predictive models) or the qualitative strength of values, beliefs and representations related to achievement.

\section{Satisfaction}

\subsection{Satisfaction and Achievement in $\mathrm{PhDs}$}

This variable has been included in several of the author's programs and complementary research projects. Here we refer to two (2) in particular, carried out with different populations though -quantitatively or qualitatively- both have been present in the majority of her studies, many of which last until current times.

If in the last century the question of Satisfaction was already important at the level of Industrial Psychology, despite the criticism that it provoked (Hertzberg, cit in House \& Wigdor,1967), today in times of uncertainty and a crisis of paradigms, the variable Satisfaction becomes particularly relevant from two angles: the individual begins to prioritize satisfaction, his free time, his schedule, and his rights; and workplaces for their part seek ways to maintain the interest and satisfaction of their personnel, linked to production, effectiveness and competitiveness.

\subsection{Satisfaction in scientists (PhDs) in the R+D System: A quantitative study}

\section{Problem}

Given the importance that the variable Satisfaction has in relation to Achievement in other contexts, there have been very few studies carried out in the field of science, and fewer still that distinguish between factors associated with Achievement in the hard sciences and in the soft sciences, according to disciplinary culture. In this sense, this study filled a void in our context (for more detail, cf. Aparicio, 2014 b). The interest that the study generated led us to extend it to the present day in the context of other projects (UNCuyo /National Science Agency). Currently there are two (2) running: a) the PICTO 20162019 Program which addresses current issues facing scientists/PhDs, those responsible for innovation; $b$ ) a study carried out in France with Argentine and other foreign PhDs and post-docs participating in academic exchanges in Paris. The objective is to analyze which factors (objective and subjective) have influenced their pathways and what impact their elected education abroad has had on national innovation.

Objective: The main objective of this research was to analyze the relationship between human (psychosocial) and material (resources) factors, and the efficiency of the Research Units (R+DUI) (Andrews, .1979). Satisfaction enters in the first group.

To achieve this, scales and indexes were developed, especially concerning the product. As far as human factors were concerned, many scales and indexes were included, especially connected with satisfaction at work.

Hypothesis: a) Satisfaction among scientists (all PhDs) is associated with Professional Mobility (the higher the position in the scientific system, the higher the satisfaction) and with the Product ${ }^{1}$. b) Satisfaction is associated with different aspects according to disciplinary fields. c) the role of leaders (bosses) of research groups is a central factor for team development and satisfaction.

\section{Methodology}

\footnotetext{
${ }^{1}$ As we will see, they were in part confirmed. They are not aspects that run in parallel. The same was observed in the study carried out with $\mathrm{PhDs}$ at Cnam and UNCuyo which we will detail below.
} 
The Sample : A stratified sample was taken from universities and different disciplines, based on a population of research teachers from the National University of Cuyo ( $N=53) \mathrm{R}+\mathrm{DU}$ : one chief or director and members.

The Techniques: Techniques were quantitative and qualitative. Two questionnaires, anecdotes and non-obstructive observation were used.

1) The Research \& Development United Questionnaire, R+DU (going forward, R+D Questionnaire), was given only to Directors who responded with data concerning the R+D United (institutional and financial resources, human resources, $\mathrm{R}+\mathrm{DU}$ age, sources of national and foreign income, scientific exchange programs and product).

2) The Core Members Questionnaire provided data related to R+DU members of the and to concrete modes of organization. It included objective data (personal and institutional-disciplinary profiles), opinions and representations of the R+DU members regarding levels of personal participation, workplace climate (dedication, cooperation, interference, etc.) and regarding employment (pressure, responsibilities and commitment). Likewise, it included opinions about budgeting and resources; satisfaction with respect to bosses (frequency of contact and effects on scientific performance and professional competencies). It also included representations of power and influence in decision-making and with respect to the effectiveness/productivity of the R+DU according to the objectives sought and the capacity for innovation, as well as to satisfaction in relation with the dissemination of results.

The Scales: Scales and indexes were created using the responses obtained for the items corresponding to variables on the Core Member Questionnaire and we then proceeded to cross them with other variables, among them Production (as an indicator of effectiveness), Professional Mobility (an indicator of achievement, particularly in the scientific and academic realms) and disciplinary fields of relevance.

Regarding that which concerns our study, we established 7 Central Scales of Satisfaction. In addition, we created a Product Scale and a Professional Mobility Scale. Detailing these scales will not be our objective here (Aparicio, 2014 b).

We will only point out that the Social Mobility Index varied between 4.67 and 100.00 , with a mean (or average satisfaction) of 53.99 and a standard deviation of 25.53 , the lowest observed.

The Index of Product was constructed by taking into account 3 clusters: Publications, Patents and Prototypes, and Reports and Algorithms.

Here we will concentrate on the Scales of Satisfaction.

Items are based on the Liker scale from 1 to 5 , with 5 being the most positive situation and 1 the most negative. The individual gave his/her opinion about each of the pairs of opposite statements $(X-Y)$, grading them as follows: 5$) X$ is applicable, 4) Tendency to $X, 3$ ) Halfway, 2) Tendency to $Y, 1) Y$ is applicable.

Let us take a look at a summary of the resulting Satisfaction Indexes and at a descriptive analysis of them, considering their level of satisfaction.

Table 1. Satisfaction Indexes.

\begin{tabular}{|l|l|l|l|l|}
\hline & Minimum & Maximum & Mean & Deviation \\
\hline Planning & 50.77 & 100.00 & 88.7590 & 10.0119 \\
\hline Atmosphere at Work & 44.71 & 96.47 & 80.5409 & 10.5910 \\
\hline Supervision/boss & 2.50 & 100.00 & 74.3000 & 26.2832 \\
\hline Level of Satisfaction with Co-workers & 6.67 & 100.00 & 63.4234 & 25.2896 \\
& & & & \\
\hline Material Factors & 21.54 & 92.31 & 61.9982 & 14.7697 \\
\hline About your Job & 35.00 & 91.67 & 61.6858 & 12.2830 \\
\hline Responsibility & 10.00 & 100.00 & 58.7059 & 28.0216 \\
\hline
\end{tabular}

As shown in the scale, the highest level of Satisfaction is present for the variables Planning (88.75) and Atmosphere at Work (80.54), whilst the index for Professional Mobility is among the lowest (53.99). 
Likewise, we constructed a General Index of Satisfaction. This varied between 25.93 and 88.89 , with a mean (or average satisfaction) of 68.72 and a standard deviation of 13.19 .

We now proceed to describe Satisfaction scales, which show significant differences ${ }^{1}$.

Scale L: About the Job: The index varied between 35.00 and 91.67 , with a mean (or average satisfaction) of 61.68 and a standard deviation of 12.28 , which indicates a moderate level of satisfaction with respect to the variable.

Scale N: Satisfaction with Chief of Research Unit: The index varied between 2.50 and 100.00, with a mean of 74.30 and a standard deviation of 26.28, which indicates a high level of Satisfaction.

Scale 0: Planning and Organization of Research Activities in the Unit: The index varied between 50.77 and 100.00 , with a mean of 88.55 and a standard deviation of 10.01, which indicates the highest level of Satisfaction in the variables considered.

Scale I: Responsibility/Attributions: The index varied between 10.00 and 100.00 , with a mean of 58.70 and a standard deviation of 28.02. These figures show one of the lowest levels of Satisfaction in the variables considered.

\section{Results}

We observed that levels of satisfaction are not independent from professional mobility and from the associated specialty domains. a) There is a significant relationship between professional mobility and satisfaction in the workplace without making a distinction between hard and soft sciences (disciplinary domains); b) Distinguishing between the two types of sciences, there exists a different association between factors of satisfaction in the workplace and professional mobility in the domains of "hard" sciences and "soft" sciences (institutional culture); c) No co-relation was found between Mobility and Product; d) And finally, the generalized non-conformism found in the mobile subjects as opposed to the team leader or boss of these scientific-academic organizations sui generis is of great interest.

We will analyze these results in three instances:

Co-relation between Professional Mobility and the Index of General Satisfaction was significant: $5 \%\left(r=.450^{\star *}, p<0.05\right)$.

Co-relation between Professional Mobility and Indexes of Satisfaction: After the scales were created and indexes calculated, the Mobility Index was co-related to the different indexes of Satisfaction. It becomes clear that there is a positive significant association between Professional Mobility and the indexes of Satisfaction at Work, Responsibility for Specific Tasks and Planning; and a negative significant association with the Boss/Supervisor.

\section{Co-relation between Professional Mobility and Satisfaction in "Hard" and "Soft" Sciences}

"Hard" Sciences: Professional Mobility is positively and significantly associated with the indexes for Job (0.48 at $1 \%)$ and Responsibility $(0.57$ at $1 \%)$. There is, in addition, a negative significant co-relation with the index for Satisfaction with bosses or directors $(-0.45$ at $1 \%)$.

"Social" Sciences: Here, a negative and significant association can only be found in the index for Satisfaction with the Supervision or the unit's leader $(-0.456$ at $5 \%)$, while there is a positive association with Planning $(0.354$ at $5 \%)$.

Analyzing the scale of co-relations (Pearson), we can see that significant associations at $1 \%$ and $5 \%$ between Professional Mobility and Satisfaction are different in the "hard" and "soft" sciences scale, which implies that each disciplinary group values different aspects of Satisfaction. In other words, the most movable subjects in "hard" sciences find Satisfaction in some aspects -typically present in their discipline- which are different from those in "soft" sciences (Crane, 1972).

There is only one aspect common to both: researchers from both fields feel they are not satisfied with the leadership in their teams (Hollander, 1971; Etzioni, 1965; Rossel, 1970; Meyer, 1976). This result can be read in light of different frameworks.

\footnotetext{
${ }^{1}$ Names in the scale remain the same as those of the previously mentioned UNESCO research study, 1971.
} 
From the Expectation-Valency theory, it is thought that the most mobile individuals (that is, those who have ascended in their career) have higher expectations and demand more than those at the top of the system (Feather \& Davenport, 1981).

From the "investment" model (Becker, 1964), it is thought that those who have ascended most expect greater benefits, many of which are linked to their position as Bosses.

Finally, it is not surprising in the current situation of structural crisis that the Index of Satisfaction with respect to Mobility is among the lowest: promotion is less likely when positions are limited. This generates non-conformism and anomy in light of the distance between the institutionalized means and goals to reach (Merton, 1968; Heintz, 1970). We see that psychosocial actors overlap with other structural actors, making linear readings difficult.

Otherwise, we find a certain homogenization or disciplinary identity for factors concerning socialization (Crane, 1972). Scientists (PhDs) from the hard sciences and those from the soft sciences only share one aspect: non-conformism with their R+DU bosses. Psychosocial and structural factors thus feed each other in the Science and Technical system.

\subsubsection{PhDs, Satisfaction and Professional Future: A French-Argentine study (qualitative-quantitative)}

\section{Problem}

Abrupt changes in the world of work and the high levels of professionalization now required demand both the implementation of new mechanisms and education in new competencies, not only disciplinary but also psychosocial competencies for management and self-management. In addition, the conditions for practicing in the professional world have changed and insertion and promotion has become a more complex issue.

To these issues are added others, such as PhD saturation in some disciplinary fields, the "plafond" effects at the professional level that result in unemployment or structural sub-employment; derived non-conformism, related especially to the lack of recognition expected, etc. Discontent also emerges from macro-national and political factors, despite having reached, many times, a high professional position (Aparicio, $2017 \mathrm{a} ; 2009 \mathrm{c}$ ). All of this has impacts at the level of identity, demanding a reconstruction of this identity (Goffman, 1963, Silva \& Aparicio, 2015).

In this framework, the link between personal pathways, educational pathways and professional pathways constitutes a source of worry. Our objective was to understand a) the objective and subjective factors (among them Satisfaction and/or Unease, VD) associated with achievement; b) the competencies and expectations of the future that define the identity profile of PhDs according to disciplinary filed, university and country.

Methodology: Quantitative and qualitative.

Population: PhD students/PhDs from Cnam (France) from three programs of study: Management, Sociology and Adult Education. At the National University of Cuyo (Argentina) we worked with PhD students/PhDs from PhD programs in Social Sciences and Education (both with sociodemographic profiles similar to those at Cnam) over the same time period.

Techniques: We used a semi-structured survey, carried out personally with PhD students/PhDs (2005-2009 period), and later updated the institutional listings. The survey included open-ended questions which allowed the actors to express themselves freely. The fundamental qualitative technique was hierarchical evocation. This allows us to capture the central representations shared by this population in relation to important nodes (for an in-depth analysis cf. Aparicio, $2009 \mathrm{e}$, Award Marie de Paris; also Aparicio et al, 2015c). In our report, we address diverse qualitative nodes linked to the value of a PhD degree and the "plus" that it provides or doesn't provide in terms of personal and professional achievement (including the satisfaction reached after obtaining the degree), representations of the world of work, objectives sought for life projects, essential values for those who lead organizations and those necessary to reach high levels of satisfaction in the workplace, among others. All of these shed light on "where" PhDs place their Satisfaction of Dissatisfaction, that is, in what spaces it is achieved (relationships with bosses, teams, required competencies versus learned competencies, the relationship with Career Mobility and Professionalization, and the relationship between Satisfaction and Positioning, among many others) (Aparicio, 2017 a,b,c).

In terms of the quantitative analysis (descriptive and correlational level) cf. Aparicio, 2009 c, Rapport Award Marie de Paris, $158 \mathrm{pp}$.

\section{Results related to the variable of Satisfaction}


Here we present a brief synthesis of our findings and the variables/dimensions associated with Satisfaction.

1. Greater professional mobility means greater satisfaction, both at Cnam ( $62 \%$ of those who reach the Director level report being Very Satisfied) and at UNCuyo (cf. Aparicio \& Cros, 2015 c, op cit, pp. 57-63). We highlight the fact that it is not only entrance which causes happiness.

2. Greater income results in greater Satisfaction.

3. Professional reorientations (narrated in interviews) served to revive and resignify their non-linear paths, sometimes cut short by unexpected situations (war, death). Those who changed their program of study reported finding satisfaction with the option (even when desertion, addressed statistically, is considered a negative aspect which affects both the individual and the quality of the education system).

4. As regards disciplinary fields, notable satisfaction emerges with the program of study and with employment, though with variations according to fields/programs of study and according to objectives sought (economic benefits, power, prestige, personal development). Nevertheless, Mobility brings with it greater Status and though this does produce objective Satisfaction, in some programs a certain subjective Dissatisfaction emerges, despite it seeming redundant. In fact, individuals were not always educated to lead, to manage competencies and programs of study, in moments when the social climate is tense and the world of work is seen by some as a ruthless struggle where competition reigns (Aparicio, 2017). These individuals are satisfied with having completed a $\mathrm{PhD}$, with having ascended to be bosses as such, but when describing this world, they do so in the worst way.

5. The majority occupies positions appropriate to their education and this creates satisfaction.

6. The value of a degree is associated with two factors: mobility and resulting satisfaction. However, the numbers are low: only between $14 \%$ and $30 \%$ say that a doctoral education results in mobility. Despite this, they report that although mobility is not reached easily, there has been an improvement in their careers (between $60 \%$ and $70 \%$ in all careers) since starting the doctorate. $20 \%$ to $38 \%$ say they have seen no progress.

This data points in the same direction as the CEREQ data. Nevertheless, the relationship between Education/Work/Mobility and the Value of a Doctoral Degree/Satisfaction continues to be the object of debate. And though tightening of the relationship between education and employment is not the norm, a positivist vision prevails.

8/ To sum up, while not denying difficulties, the majority are satisfied with their degree and/or doctoral studies and, though these do not always imply economic benefits, they continue to have value at the symbolic level. In this sense, the value seems more symbolic in France than in Argentina. Here PhDs still hope for a brighter future for the sole fact of having reached the $\mathrm{PhD}$.

\subsection{Satisfaction and Achievement for Teachers}

\section{Introduction}

A number of comparative studies have been carried out with this population at the university, tertiary and secondary levels (cf. Aparicio, 2017 and 2018: this article contains a synthesis of all studies completed).

In these studies, we address the issue of teaching from two large dimensions: a) the philosophical bases that underlie the different stages of development of teacher education, political-institutional, historical and legal aspects; b) using empirical studies in the field to understand these issues in vivo, teachers' concerns, the system's demands (professionalization, rights, etc.); all of these aspects that define a teaching identity.

\section{Methodology}

Fundamentally, we used a qualitative methodology (interviews and hierarchical evocations). The quantitative techniques used included institutional listings and semi-structured surveys that included open-ended questions to allow participants to speak freely. 


\section{Results}

Globally: among the "non-variants" or common aspects -shared and expressed through social representations- we observed that:

Teachers are satisfied with aspects related to the affective and relational dimension (bonds, interaction). Their achievement is found within the context of their vocation and decisions: within their life project they opted for personal fulfillment and not for economic benefits, prestige or power in their profession (Becker, 1964, "consumption" model versus "investment" model).

There are also dissatisfied individuals who demonstrate a certain level of discontent because of greater social demands (particularly, on behalf of families and the media) and because of the increased presence of violence and lack of respect (Aparicio, 2011 a, b 2013)

It is also important to note that we have found issues common to both the Argentine and French contexts, demonstrated by common expressions and/or words used.

Finally, in line with the author's strategy of analysis -micro-meso-macro-micro-, we observe that the historic problem of identity in the teacher education system, a system which has been weakened and fragmented by political decisions, falls back on teachers themselves, which further weakens their identity. We find fragmented identities at the macro-national and meso-institutional levels and ruptured identities at the micro level which in some cases in France go so far as to lead to early abandonment of the goal (Aparicio 2009 c; 2012; 2015 a, b; 2017 e; Silva \& Aparicio, 2015).

\section{Resilience or the importance of "social competencies" to university achievement. The case of students who prolong their studies.}

We will now detail some of the research studies carried out, quantitatively and qualitatively.

\subsection{Negative performance: a quantitative study of individuals who extend their studies ${ }^{1}$}

\section{Introduction}

As were previous studies, this research was carried out within the general framework of improvement in Educational Quality as linked to Negative Performance. We used a sample of individuals that extend or delay their studies at six schools (1985-2004), with the objective of understanding what factors/dimensions influenced this decision of extension. The statistics are alarming: only $17 \%$ of the students graduate, $60 \%$ drop out and the rest extend their studies. This problem represents material and human cost in terms of frustration.

What concerns us in this article, which attempts to show the importance of resilience through empirical studies, are the characteristics of our university education, very focused on the disciplinary aspect, which can be found at the base of the "relative failure" statistics, impacting the "low institutional and learning quality". In fact, though there are differences according to program of study, education in "social competencies" is frequently forgotten. These competencies, studied by the author for at least 15 years, include: communicational competencies, coping strategies, and resilience, among others (Aparicio, $2016 \mathrm{a}, \mathrm{b}$ ).

Resilience develops social bonds, relational competencies which will be very useful in the university, in the workplace and in life in general. It is defined as an individual's ability to react to adverse and sometimes unexpected situations and to overcome obstacles. It implies a set of sub-factors that favor success when one is faced with the changes and processes of adaptation which these suppose, evermore necessary in current times.

\footnotetext{
${ }^{1}$ We must point out that in this research on University Student Delay, Satisfaction in the workplace was also part of the predictive model, appearing as a factor in line with the extension of studies. In effect, at times when it is difficult to find a job and feel satisfied, students opt to work and prolong their studies. (Cf. Aparicio, 2009 b, cit., Levy-Garboua, 1976).

In addition, Satisfaction and Self-Esteem were analyzed as part of the author's second doctoral thesis (Sorbonne, 2005) as factors linked to achievement in quantitative-predictive models. Results were calculated in detail according to univariate and bivariate analyses. Cf. Aparicio, 2009 (published thesis).
} 
Here we cannot go into the theory (cf. Aparicio 2007 b). However, it is important to highlight the fact that this ability to resist pressure which allows for a healthy life in adverse environments entails: a) a set of social and intra-psychic processes, and b) concerns not only individuals but also, equally, groups and institutions. It is not an innate ability, it is the result of a personal and institutional construction that reaffirms a belief in one's own efficacy to solve problems and adapt to changes (Hemández, 1998; Puerta de Klinkert, 2002).

All of these aspects and/or competencies are precisely those which are currently being prioritized by the educational systems that lead quality rankings. In the line of positive performance, these studies carried out with university students demonstrate resilience to be the most important factor for "negative performance" in the models (cf. Studies on 'delay', Aparicio 2009 a, b).

Briefly, as the foundation for achievement, including disciplinary achievement, we find the social competencies, of being and living (listening, companionship, bonds and affects, emotional intelligence). Added to these are the cognitive-procedural competencies (flexibility, the ability to reflect, make decisions and act, cf. Aparicio, 2007 a; 2016 b). It will be impossible to change the way of working at school, ,at university and at work without improving human relations, without giving new value to the individuals in educational institutions or workplace organizations, without developing their unique potential, withoiut sharing and reflecting by setting aside selfish motives, and without developing creativity or encouraging motivation (Argyris, 1982). It will be impossible to replace retrospective representations of ways of acting for others considered more appropriate (at the level of administration/teachers, teachers/students, bosses/operators). It will be impossible to negotiate, knowing that something is always lost but more is gained in these new exchanges, for oneself, for one's life, for the life of the group and for life as citizens. At times when depersonalization reigns and the term personality has even begun to fall into disuse, it is important to give new value to the individual. On the contrary, in recursive returns or feedback, the individual (consciously or subconsciously) goes against the micro or macro system, generating negative results, at least from the author's systemic perspective sui generis.

Change must start from all spheres, as well as from oneself and from critical reflection on one's own practices, not always expecting directives from outside sources. Without this, there will be no teacher or educational reform that improves the quality of learning for life.

Objective: to understand the relationship between Resilience and achievement for individuals who extend their studies.

Specific Hypothesis: High levels of resilience (RESIL) - favored by instances of socialization (family, school, etc.) and by concrete instances of education - will generate profiles more favorable to achievement.

Methodology: quantitative and qualitative. Here we will make reference to our quantitative findings.

Population: 229 subjects from six schools at the UNCuyo (1985-2004).

Techniques: we used a semi-structured survey with open-ended questions. We also used specific tests to measure psychosocial and other variables in relation to university achievement (RU, measured with a compound index); concretely: Coping Strategies to face difficulties, attributional styles, motivational factors and Resilience (Henderson \& Milstein, 2003 Questionnaire). We worked at a descriptive level (resilience according to school/program of study), bivariate and multivariate (cf. Studies on delay, volume 1).

The Questionnaire used is composed of three scales: Students (RESIALUM), Personnel - administration and teachers - (RESIPERS) and Institutions - schools - (RESIFACU). In addition, it was divided into six sub-scales that can be regrouped into two dimensions. The aspects evaluated here are two: A) Mitigate Risk: 1. Enrich prosocial links; 2 . Set clear and firm limits; 3. Teach competencies for life (cooperation, conflict resolution, communicational competencies and healthy ways to manage stress). B) Build Resilience: 1. Give affection and support; 2. Establish and convey realistic expectations and avoid the plafond notion for development; 3. Provide meaningful opportunities for participation (problem solving, definition of objectives and goals, helping others).

\section{Results}

The results demonstrate the role that resilience plays in academic achievement (here, in lengthening studies).

For the three scales, Students (RESIALUM), Personnel - administration and teachers - (RESIPERS) and Institutions Schools - (RESIFACU) ${ }^{1}$, the mean is concentrated in category 3 , which indicates that Resilience is currently in the initial

\footnotetext{
${ }_{1}^{1}$ Variables have a point-value: Number 1 indicates the individual is doing ok, 2 . he advanced, 3 . he is beginning, 4. nothing has been done. Elevated point-values, 0 those above 48, demonstrate that the student (in our research) evaluates his resilience as null or nonexistent. On the contrary, the minimum value for the student/personnel/institution scales is 12 , which shows that the student evaluates resilience taught as something positive, he understands his institution to be a generator of resilience.
} 
stages, with very low values. Generally speaking, this means that at all Schools, Resilience is low for Students, Personnel and for the Institution itself. Nevertheless, each school has its own profile or identity, with some generating more Resilience than others (Aparicio, 2007 b). This fact demands a situated, contextualized analysis (interaction between the mesoinstitutional and individual levels). Therefore there must be spaces that generate resilience (Schools/Programs of Study in our research) and that favor its emergence.

\subsection{Negative performance: a qualitative study of individuals that extend their studies}

A complete volume of research work (more than 500 pages) with individuals who delay their studies is dedicated to the treatment of data and qualitative findings. Among these findings, many refer to resilience and to "low resilience" rates developed to face obstacles and reach the goal of graduation in the time stipulated by the Plan of Study. Individuals refer to the lack of precise life projects, the absence of clear goals, entering a program that was not his/her first choice only to "try it out" and when not feeling comfortable, dropping out. They also said that they were influenced by the situation many graduates in the workforce are struggling with: that a diploma does not currently ensure better job positions and if they do get a job, or even without one, many decide to prolong their studies (Levy Garboua, 1976, theory of differed gratification). Once more, we observe that much achievement depends on the individual, on the person in contexts which condition but do not determine. In effect, the entire system could change (increase infrastructure, nighttime course schedules for those students who work, etc.). However, if an individual decides not to prioritize his/her studies, he or she will extend their studies despite reforms to the system. A return to the individual from a "situated" context? The individual, his/her values (cultural factors), motivations and decisions (psychosocial factors), according to the findings, play a key role.

Finally, the influence context has is particularly observed in the qualitative analysis. Individual and context are in interaction in a movement that may or may not be enriching for both. Here, the responsibility that institutions have as generators of this competence emerges, despite the structural or current limitations that will always exist. Socialization emerges in the heart of the results in this line of development.

\subsection{Resilience in other research studies}

In other studies, this factor was measured qualitatively, using the technique of hierarchical evocation, and was observed through the value of the links, support, and companionship of the extracurricular experiences that strengthen and/or create solid bonds, among many other aspects (Cf. PICTO 2010, interinstitutional research program carried out on Retention, a positive facet of achievement cf. Aparicio (Dir.) 2015 d).

These aspects, using well-known models produced in the US over the last century, appear as central factors linked to achievement (in a positive sense, as is the case of retention and graduation, or a negative sense, as is the case of dropping out). (The first refers to Aparicio, 2007; 2015 a; in both publications there is a synthesis of research with dropouts. See also, cf. Aparicio 2014a. Here we refer to the primary global models on the subject, where the supra aspects cited are decisive and findings are interpreted in light of the author's theory: The Three-Dimensional Spiral of Sense).

\section{Conclusion}

The findings show that the learning paradigm implies the development of soft abilities/competencies at its base. Without developing these, learning becomes difficult, either because of a lack of interest or a lack of strategies to overcome adversity. And said abilities/competencies are generated in an individual within contexts favorable to development, later resulting in an improvement of institution and macro national quality.

\section{References}

[1] Agasisti, T. et al. (2018), "Academic resilience: What schools and countries do to help disadvantaged students succeed in PISA", OECD Education Working Papers, No. 167, OECD Publishing, Paris. http://dx.doi.org/10.1787/e22490ac-en

[2] Andrews, F. M. (ed.) (1979). Scientific Productivity: the Effectiveness of Research Groups in Six Countries. Cambridge: Cambridge University Press; Paris: UNESCO.

[3] Aparicio, M. (2007). Mobilité et réussite universitaires et professionnelles. Du niveau macro au niveau micro. HDR en Sciences de l'éducation. Université París X, Nanterre, France.

[4] Aparicio, M. (2009 a). La demora en los estudios universitarios. Causas desde una perspectiva cuantitativa Tome I. Mendoza: EDIUNC.

[5] Aparicio, M. (2009 b). La demora en los estudios universitarios. Causas desde una perspectiva cualitativa. Universidad Nacional de Cuyo. Tome II. Mendoza : EDIUNC. 
[6] Aparicio, M. (2009 c). Conference. « La formation des enseignants : tableau de la situation en Argentine et perspectives dans le cadre de la coopération bilatérale ». Symposium International de l'IRPE, 20-21th October, Sherbrooke, Canada.

[7] Aparicio, M. (2009 d). Les facteurs psychosociaux et la réussite universitaire et professionnelle. Université de Lille 3: ANRT.

[8] Aparicio, M. (2009 e). Le devenir professionnel des étudiants qui sont engagés dans un doctorat en éducation/formation. Une approche comparative franco-argentine». Rapport. Award. Marie de Paris.

[9] Aparicio, M. (2011 a). Professional Identity Crisis, Social Identity Crisis. Acta Europeana Systemica, Revue en ligne de I'Union Européenne de Systémique (UES). Mise en ligne le 07 décembre 2011, Vol. 1.

[10] Aparicio, M. (2011 b). Teachers' Professional Development at University and High School: An Interactive Relationship between Subjects and Socio-institutional Contexts. Acta Europeana Systemica, Revue en ligne de l'Union Européenne de Systémique (UES), Mise en ligne le 07 décembre 2011, Vol. 1.

[11] Aparicio, M. (2012). Trajectoires universitaires/professionnelles et identité. In J. Clénet, Ph. Maubant et D. Poisson (Eds.). Formations et professionnalisations: à l'épreuve de la complexité. Paris: L'Harmattan, 195-229.

[12] Aparicio, M. (2013). Formación de formadores y Profesionalización en Argentina: Un análisis de la situación macro-social, méso-institucional y su impacto sobre las trayectorias e identidad de los formadores. In: A. Arbós et P. Puig Calvó (Eds.). Universidad y Sociedad: Formación y Profesionalización, Barcelona: Furtwangen, 195- 209.

[13] Aparicio, M. (2014 a). University Drop-Outs. A Systemic Play of Subjects, Institutions and Macro Contexts. Journal of Educational and Social Research Vol 4, No 2.

[14] Aparicio, M. (2014b). Satisfaction, Professional Mobility and Leadership in Academic-Scientific Organisations, Journal of Health Science, 28(3), 135-145

[15] Aparicio, M. (2015 a). Towards a sui generis Systemic Theory: The Three-Dimensional Spiral of Sense. A Study in Argentina Applied to Identity and Professionalization (Part I). Asian Academic Reseach Journal an Social Science and Humanities, 2(8), (December 2015), 246-282.I

[16] Aparicio, M. (2015 b). The Theory of the Three-Dimensional Spiral of Sense: An Application with special Reference to Identity and Professionalization in other Disciplinary Areas (Part 2). Asian Academic Research Journal of Social Sciences \& Humanities, 2(8), (December 2015), 194-245.

[17] Aparicio, M. \& Cros, F. (2015 c). Trajectoires et identités. Un avenir incertain pour les docteurs? Paris: L'Harmattan.

[18] Aparicio et al. (2015 d). Social Competences and Organisational Devices in their Relationship with of University Studens' Retention. In Carmo, M. (2015) (Ed.). Education Applications \& Developments 13. Portugal: InScience Press. Vol. II, Chapter 17, 185-195.

[19] Aparicio, M. (2016 a). Resiliency, Professionalization and Identity. A Study in Relation to Achievement at University at the Light of a New Paradigm: The Spiral Three Dimensional of Sens. European Journal of Multidisciplinary Studies (EJIS), JanApr., vol 4(2), 126-131.

[20] Aparicio, M. (2016 b). Les facteurs psychosociaux à la base de la réussite universitaire et professionnelle Aspects psychologiques et organisationnels. Editions Universitaires Européennes, Dusseldorf, Germany.

[21] Aparicio, M. (2017 a). Expectations, Satisfaction and Professional Achievement. An Analysis of their Relation in light of a New Systemic Paradigm: The Three-Dimensional Spiral of Sense. European Journal of Social Sciences Education and Research (EJSER), n² 2, January-April, 54-60.

[22] Aparicio, M. (2017 b). Intergenerational Educational Mobility of PhDs and the "Plafond" Effects: A French-Argentine Comparative Study. International Journal of Humanities and Social Science, 7( 8), 58-65. August 2017.

[23] Aparicio, M. (2017 c). Professional/Occupational Mobility and Doctors Carriers (France and Argentina). International Journal of Research in Social Sciences. October 1, 11(2), 178-194.

[24] Aparicio, M. (2017 d). Need-Achievement, Expectations and Life Purpose: A French-Argentine Study of PhDs in Education. International Journal of Research in Social Sciences, October 1, 7(10), 167-178.

[25] Aparicio, M. (2017e). Formation de formateurs: Identité et professionnalisation. Une analyse à travers un modèle systémique sui generis "Tthe Three-Dimensional Spiral of Sens". Acta Europeana Systemica. Journal of the European Union for Systemic (EUS), n07. UES-EUS, AFSCET, S\&O, HSSS, AIRS, SESGE joined issue, Décembre 2017).

[26] Aparicio, M. (2018). Teacher Identity and Sociopolitical and Professionalization Demands. An Analysis of Their Relation in Light of a New Systemic Paradigm: The Three-Dimensional Spiral of Sense. European Journal of Social Sciences Education and Research, Jan. Apr. 2018, 12(1), 42-52.

[27] Argyris, C. (1982). Learning and Action: Individual and Organizational. San Francisco: Jossey-Bass.

[28] Becker, G. (1964). Human Capital, Columbia University Press, New York / London.

[29] Crane, D. (1972). Invisible Colleges. Chicago. University Chicago Press.

[30] Boudon, R. (1973). L'inégalité des chances. Paris : PUF.

[31] Bourdieu, P. \& Passeron, J-C- (1979). La reproducción. Barcelona: Laia.

[32] Chernyshenko, O., M. Kankaraš and F. Drasgow (2018), "Social and emotional skills for student success and wellbeing: Conceptual framework for the OECD study on social and emotional skills", OECD Education Working Papers, No. 173, OECD Publishing, Paris. http://dx.doi.org/10.1787/db1d8e59-en

[33] Dubar, C. (1995). Pour une approche compréhensive à la promotion sociale. Pour, 148.

[34] Etzioni, A. (1961). A Comparative Analysis of Complex Organizations. American Sociological Review, 30, 692-698. 
[35] Feather, N. \& Davenport, P. (1981). Unemployment and Depressive Effect: a Motivational and Attributional Analysis. Journal of Personality and Social Psychology, 41(3), 422-436.

[36] Goffman, E. (1963). Stigmates. Paris : Minuit.

[37] Heintz, P. (1970). Hacia un paradigma sociológico del desarrollo en América Latina. Buenos Aires: Instituto.

[38] Henderson, N. \& Milstein, M. (2003). Resiliencia en la escuela. Buenos Aires: Paidós.

[39] Hollander, E. (1971). Style, Structure and Setting in Organizational Leadership. Administrative Science Quaterly, 16(1), 119.

[40] House \& Wigdor (1967). Herzberg's Dual-Factor Theory of Job Satisfaction and Motivation: A Review of the Evidence and the Criticism. Personal Psychology, 20, 369-389.

[41] Levy-Garboua, L. (1976). Les demandes de l'étudiant ou les contradictions de l'université de masse, Revue française de sociologie, 17(1), 53-80.

[42] Martucelli, D. (2002). Les grammaires de l'individu. Paris: Gallimard.

[43] Meyer, L. (1976). Leaderships and Organizational Structure. American Journal of Sociology, 81(3), 514-542.

[44] Mostafa, T. and J. Pál (2018), "Science teachers' satisfaction: Evidence from the PISA 2015 teacher survey", OECD Education Working Papers, No. 168, OECD Publishing, Paris. http://dx.doi.org/10.1787/1ecdb4e3-en

[45] OECD. World Economic Forum "Futur of job report". https://www.infobae.com/educacion/2018/01/14/cuales-son-los-paisesque-mejor-se-preparan-para-el-trabajo-del-futuro/ Consultado 2 de mayo 2018.

[46] PISA. http://www.oecd.org/pisa/pisaenespaol.htm. Consultado 2 de mayo 2018.

[47] Puerta de Klinkert, M. P. (2002). Resiliencia. Buenos Aires: Lumen.

[48] Rossel, R. (1970). Instrumental and Expressive Leadership in Complex Organisations. Administrative Science Quaterly, 15(3), 306-316.

[49] Shön, D. (1992). La formación de profesionales reflexivos. Hacia un diseño de la enseñanza-aprendizaje en las profesiones. Madrid: Paidós lbérica.

[50] Silva, A. M. \& Aparicio, M. (Eds.) (2015 b). International Handbook about Professional Identities. New York: Academic and Scientific Publishing.

[51] UNESCO (1971). International Comparative Study in Organizations and Perfomance of Research Units, Paris: UNESCO. 